\title{
Co-induction of hepatic IGF-I and progranulin mRNA by growth hormone in tilapia, Oreochromis mossambiccus
}

\author{
Mark Hung-Chih Chen ${ }^{\mathrm{b}, 1}$, Yen-Hsing Li ${ }^{\mathrm{a}, 1}$, Yvonne Chang ${ }^{\mathrm{a}}$, Shao-Yang $\mathrm{Hu}^{\mathrm{a}}$, \\ Hong-Yi Gong ${ }^{\mathrm{a}}$, Gen-Hwa Lin ${ }^{\mathrm{a}}$, Thomas T. Chen ${ }^{\mathrm{e}}$, Jen-Leih Wu ${ }^{\mathrm{a}, \mathrm{c}, \mathrm{d}, *}$ \\ ${ }^{a}$ Laboratory of Marine Molecular Biology and Biotechnology, Institute of Cellular and Organismic Biology, Academia Sinica, Taipei 115, Taiwan \\ ${ }^{\mathrm{b}}$ Bioluminescence in Life-image Laboratory, Department of Biotechnology, Institute of Biotechnology, Hungkuang University, Shalu, Taichung 433, Taiwan \\ ${ }^{\mathrm{c}}$ Graduate Institute of Life Sciences, National Defense Medical Center, Taipei 114, Taiwan \\ ${ }^{\mathrm{d}}$ Institute of Microbiology and Biochemistry, National Taiwan University, Taipei 110, Taiwan \\ ${ }^{\mathrm{e}}$ Department of Molecular and Cell Biology, University of Connecticut, Storrs, CT 06269, USA
}

Received 28 May 2006; revised 16 August 2006; accepted 19 August 2006

Available online 2 October 2006

\begin{abstract}
Like IGF-I, progranulin (pgrn) is a growth factor involved in tumorigenesis and wound healing. We report here the identification and characterization of pgrn cDNA in tilapia and the regulation of its expression by growth hormone (GH). The tilapia pgrn cDNA was cloned by RT-PCR amplification, using gene specific oligonucleotides as amplification primers. The cDNA contains an open reading frame encoding a peptide of 206 amino acid residues (aa) that contains a presumptive signal peptide (23 aa) and two repeat units of granulin (grn, 51 and 52 aa, respectively) franked by a GAP of 49 aa and the carboxyl terminus with 31 aa. The two predicted grn peptides are arranged in tandem repeats interrupted by a GAP peptide. RT-PCR analysis revealed that high levels of prgn mRNA were present in several tissues such as spleen, gastric cecum, intestine, fat tissue, gill, kidney, eye and pancreas, and lower levels in liver, muscle, heart, brain, skin and stomach. Administration of a single dose (500 ng/g body weight) of recombinant seabream growth hormone (rbGH) by intraperitoneal (ip) injection into one-month-old tilapia resulted in an obvious increase of IGF-I and pgrn mRNA (2.7-fold and 2.5-fold, respectively) in the liver at three hours post-GH treatment. The peptide levels of pgrn in the liver of GH-treated fish also were substantially induced over controls at $12 \mathrm{~h}$ post-GH treatment as detected by western immuno-blot analysis. The co-induction of IGF-I and pgrn following GH treatment may suggest the involvement of pgrn in GH regulated growth in tilapia.
\end{abstract}

(C) 2006 Elsevier Inc. All rights reserved.

Keywords: Growth hormone; Pgrn; IGF-I; Tilapia; Induction; Zebrafish

\section{Introduction}

Growth in vertebrates involves complex interactions of genes, metabolism, nutrition and hormones (Nijhout, 2003). It was previously believed that body growth in vertebrates was controlled by GH produced in the pituitary gland and mediated by circulating IGF-I or somatomedin C produced in the liver (Le Roith et al., 2001). In fish and other higher verte-

\footnotetext{
* Corresponding author. Fax: +886227824595.

E-mail addresses: blackfish@sunrise.hk.edu.tw (M.H.-C. Chen), Thomas. Chen@uconn.edu (T.T. Chen), jlwu@gate.sinica.edu.tw (J.-L. Wu).

${ }^{1}$ These authors equally contributed to this work.
}

brates, liver production of IGF-I is a major point of body growth control via the GH/IGF axis (Le Roith et al., 2001; Shamblott et al., 1995). However, the somatomedin hypothesis did not consider the possible involvement of IGF-I produced by paracrine or autocrine sources. In liver specific IGF-I gene knock-out mice, postnatal growth and development are nearly normal, despite the marked reduction of circulating IGF-I and IGF-binding protein levels (Butler and LeRoith, 2001). Moreover, the importance of GH and IGF-I in controlling postnatal growth was demonstrated further in GH receptor/IGF-I double knock-out mice in which the body weight retardation was more severe than that observed from a single knock-out of GH or IGF-I. In fact, the body weight of 
these double knock out mice is only $17 \%$ of the wild type (Lupu et al., 2001). Based on these studies, it is obvious that the body growth is controlled not only by the GH and IGF-I source $(83 \%)$, but also by a non IGF-I and GH source $(17 \%)$.

Gene inactivation in a rodent model clearly indicates the importance of type 1 insulin-like growth factor receptor $(\text { IGF-IR })^{2}$ in fetal growth. Studies conducted by Liu et al. (1993) and Baker et al. (1993) showed that the introduction of disrupted IGF-IR into mice resulted in animals weighing $45 \%$ of the normal weight and failed to survive at birth. It has been known for years that the action of insulin-like growth factors (IGF-I and IGF-2) are mediated primarily by the activation of the IGF-IR, which is the key regulator of IGF signaling (Chen et al., 2004; Le Roith et al., 1995). Although IGF-IR is ubiquitously expressed in many cell types, mature B cells and hepatocytes do not express IGF-IR (Rechler, 1997; Romano, 2003). Xu et al. (1998) recently demonstrated that the granulin/epithelin precursor is a growth factor, secreted by a variety of epithelium cells, hemopoietic cells and hepatocytes, and it is the only growth factor that can stimulate growth in the IGF-IR ${ }^{-}$cells. The granulin/ epithelin family of protein molecules is a novel class of growth regulators with possible roles in development, inflammation, wound healing and tissue remodeling (Ashcroft et al., 2000; He et al., 2003; Shoyab et al., 1990). Results of in vivo and in vitro studies further indicated that cell growth, regulated by pgrn, is dependent upon the phosphorylation of the mitogen-activated protein kinase (MAPK) (He and Bateman, 1999; Liau et al., 2000; Nijhout, 2003; Romano, 2003; Xu et al., 1998). Although the multifunctionality of pgrn has been well demonstrated, the factor(s) that regulate pgrn have yet to be identified. While the cDNA corresponding to IGF-I has been studied in many teleost species (Chen et al., 2001), the cDNA of pgrn only has been isolated from only a few fish species (Barreda et al., 2004; Belcourt et al., 1993; Hanington et al., 2006). Furthermore, though both pgrn and $\mathrm{GH}$ are members of the hemopoietin superfamily (Miller and Eberhardt, 1983), it is unclear whether GH regulates the expression of pgrn. Using tilapia as experimental animals, we have attempted to determine the functional relationship between GH and pgrn. In this paper, we report the cDNA sequence of pgrn and the expression of pgrn mRNA and protein in response to induction by GH.

\section{Materials and methods}

\subsection{Injection of recombinant seabream growth hormone ( $r b G H)$ and tissue RNA preparation}

Juvenile tilapia (Oreochromis mossambicus) weighing about $1.2 \mathrm{~g}$ were held at $28^{\circ} \mathrm{C}$ for 1 month and fed daily to satiation. After starvation for 2 days, the fish were anesthetized in 2-phenoxyethanol (Sigma; P-1126) and then given an ip injection of 10,100 , or $500 \mathrm{ng}$ of rbGH (Gropep, Austradia)

\footnotetext{
${ }^{2}$ Abbreviations used: GH, growth hormone; proIGF-I, pro-insulin-like growth factor I; IGF-IR, type 1 IGF receptor; Pgrn, progranulin; grn, granulin; MAP, mitogen-activated protein; nt, nucleotide; bp, base pair; $\mathrm{kb}$, kilobase pair; aa, amino acid.
}

per gram of fish body weight or phosphate-buffered saline (PBS; $0.008 \mathrm{M}$ $\left.\mathrm{Na}_{2} \mathrm{HPO}_{4}, 0.0015 \mathrm{M} \mathrm{KH}_{2} \mathrm{PO}_{4}, \mathrm{pH} 7 / 0.137 \mathrm{M} \mathrm{NaCl}, 0.0027 \mathrm{M} \mathrm{KCl}\right)$. Principles of animal care were followed under the regulation of Academia Sinica (Taiwan). Tissues samples were collected from three GH-treated and three control fish prior to hormone injection $(0 \mathrm{~h})$ and at $1,3,6,12,24 \mathrm{~h}$ after hormone injection ( $n=3-4$, at each time point). Tissue total RNA was extracted from $100 \mathrm{mg}$ of liver by using RNAzol ${ }^{\mathrm{TM}} \mathrm{B}$ reagent (Tel-Test, Friendswood, TX) based on the acid guanidinium thiocyanate phenol-chloroform extraction method (Chomczynski and Sacchi, 1987), following the manufacturer's protocol. Final RNA concentrations were determined by optical density measurement at $260 \mathrm{~nm}$, and the RNA integrity was verified by ethidium bromide staining of $28 \mathrm{~S}$ and $18 \mathrm{~S}$ ribosomal RNA bands on a denaturing agarose gel. Total RNA, after treatments with DNase $\left(10 \mathrm{IU}\right.$ at $37^{\circ} \mathrm{C}$ for $10 \mathrm{~min}$, MBI Fermentas), was divided into aliquots and stored at $-80^{\circ} \mathrm{C}$.

\subsection{Synthesis of the DNA probes and Northern RNA blot analysis}

For RNA Northern blot analysis, DNA probes were synthesized from the cDNA of IGF-I (AF033796) and Est of pgrn (DQ861906). Liver RNA $(25 \mu \mathrm{g})$ was electrophoresed in 1\% formaldehyde/formamide RNA gel at $90 \mathrm{~V}$ for $3 \mathrm{~h}$, and transferred onto nylon membrane with a TURBOBLOTTER $^{\text {TM }}$ (Schleicher \& Schuell). Deoxynucleotide probes were randomly labeled with $\left[\alpha-{ }^{32} \mathrm{P}\right] \mathrm{dCTP}(3000 \mathrm{Ci} / \mathrm{mmol}$; NEN) according to instructions from Amersham. The probe was adjusted to a specific activity of approximately $4 \times 10^{6} \mathrm{cpm} / \mathrm{ml}$. The RNA blot membrane underwent prehybridization, hybridization and washing at $42^{\circ} \mathrm{C}$ according to the manufacturer's protocols (ULTRAhyb ${ }^{\circledR}$ from Ambion). The hybridization signals were detected in a Typhoon 9410 Imager (Amersham).

\subsection{3'RACE of tilapia pgrn $c D N A$ sequence}

Rapid amplification ( $3^{\prime}$ RACE) of the pgrn cDNA from the $3^{\prime}$ end of the RNA was performed with the 3'RACE System (Invitrogen, USA) according to the manufacturer's protocol. A gene specific primer (P1: 5'-TCCAG GAGCT TAAAGAGAGC CACGTCCC-3') of tilapia pgrn for $3^{\prime}$ RACE (P1) was designed from the sequence of tilapia pgrn Est clone (DQ861906). First strand cDNA was synthesized from $1 \mu \mathrm{g}$ of liver RNA, using oligo(dT) (Invitrogen, USA) as a reverse transcription primer according to manufacturer's protocol. Double strand cDNA of pgrn was prepared by PCR amplification of the first-strand cDNA using oligonucleotides P2F (5'-GAAGGA GTAGAAAGAAAGTGTGAAAGGC-3') and P2R (5'-CCTGTGTCCC TTCTTCTAGTTTTCTTTG-3') designed from the sequence of tilapia grn Est clone (DQ861906) as amplification primers.

\subsection{Semi-quantification RT-PCR}

Levels of pgrn mRNA were determined by semi-quantitative RT-PCR using $18 \mathrm{~S}$ ribosomal RNA as an internal standard. The intensity of the pgrn amplification product increased up to 45 cycles, whereas $18 \mathrm{~S}$ rRNA reached a plateau at 40 cycles with liver RNA samples. Therefore, in order to best determine the levels of pgrm mRNA and $18 \mathrm{~S}$ rRNA, the amplification cycle was set at 35 cycles. One microgram of total RNA was denatured at $70^{\circ} \mathrm{C}$ for $10 \mathrm{~min}$ and converted into cDNA at $42^{\circ} \mathrm{C}$ by Superscript ${ }^{\mathrm{TM}}$ II RNase H Reverse Transcriptase (Invitrogen, Carlsbad, $\mathrm{CA}$ ) using oligo-dT as the reverse transcription primer. After the reaction, the samples were heated at $70^{\circ} \mathrm{C}$ to terminate the reaction. The resulting cDNA was subsequently amplified with 2 units of Taq DNA polymerase (Prozyme, Finland) in $50 \mu \mathrm{l}$ of master mix containing $1 \times$ PCR buffer, $1.5 \mathrm{mM} \mathrm{MgCl} 2,2.5 \mathrm{mM}$ dNTPs, and $10 \mathrm{pmol} / \mathrm{ml}$ of pgrn specific primers (Forward: 5'-GAAGGAGTAG AAAGAAAGTG TGAAAGGC-3'; Reverse: 5'-CCTGTGTCCC TTCTTCTAGT TTTCTTTG-3') or $18 \mathrm{~S}$ rRNA specific primers (Forward: 5'-TTTCGAGGCC CTGTAATTGG-3'; Reverse: 5'-GGGCTGGGAC AGACGGTAG-3'). PCR amplification was carried out for 35 cycles in an automated thermocycler (PCR, ABI, 2400). RNA samples isolated from three different animals were analyzed by three different independent RT-PCR reactions and the results were expressed as the mean of the ratio of pgrn over $18 \mathrm{~S}$ rRNA \pm standard deviation (SD), using the BioRad ${ }^{\mathrm{TM}}$ Quantity One ${ }^{\circledR}$ software. 
A

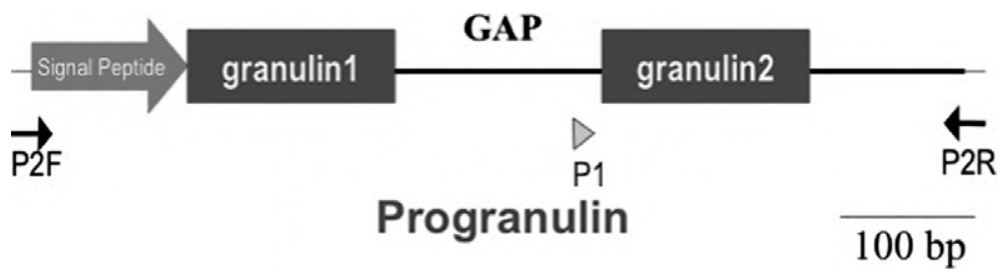

B

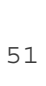

101

151

201

251

301

351

401

451

501

551

601

651

701

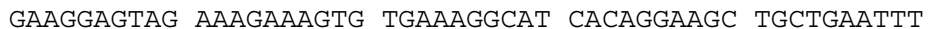
\begin{tabular}{llllllllllll}
$M$ & $\mathrm{~L}$ & $\mathrm{R}$ & $\mathrm{I}$ & $\mathrm{T}$ & $\mathrm{L}$ & $\mathrm{C}$ & $\mathrm{L}$ & $\mathrm{S}$ & $\mathrm{F}$ & $\mathrm{G}$ & $\mathrm{V}$ \\
\hline
\end{tabular} CTTCACTGCC TAAAGATGTT GAGGATCACT CTGTGTTTGT CATTCGGTGT

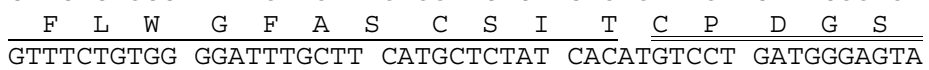
\begin{tabular}{lllllllllllllllll}
$\mathrm{T}$ & $\mathrm{C}$ & $\mathrm{S}$ & $\mathrm{D}$ & $\mathrm{T}$ & $\mathrm{A}$ & $\mathrm{T}$ & $\mathrm{C}$ & $\mathrm{C}$ & $\mathrm{K}$ & $\mathrm{A}$ & $\mathrm{K}$ & $\mathrm{I}$ & $\mathrm{G}$ & $\mathrm{F}$ & $\mathrm{G}$ & $\mathrm{C}$ \\
\hline \hline
\end{tabular} CTTGTTCAgA CACCGCCACC TGCTgCAAgG CTAAAATCGg CTTTGgCTGC \begin{tabular}{lllllllllllllllll}
$\mathrm{C}$ & $\mathrm{P}$ & $\mathrm{F}$ & $\mathrm{P}$ & $\mathrm{H}$ & $\mathrm{A}$ & $\mathrm{M}$ & $\mathrm{C}$ & $\mathrm{C}$ & $\mathrm{A}$ & $\mathrm{D}$ & $\mathrm{L}$ & $\mathrm{L}$ & $\mathrm{H}$ & $\mathrm{C}$ & $\mathrm{C}$ & $\mathrm{P}$ \\
\hline \hline
\end{tabular} TGCCCATTTC CACATGCCAT GTGCTGTGCC GAtCTGCTCC ACTGCTGCCC

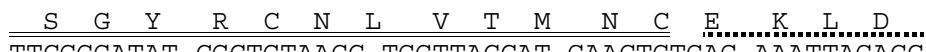

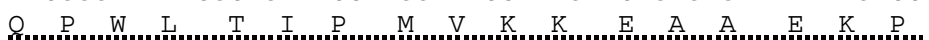
AGCCGTGGCT GACCATACCC ATGGTGAAGA AGGAGGCTGC GGAGAAACCA

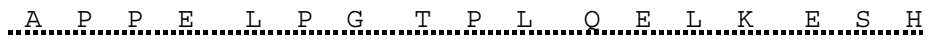
GCCCCACCTG AACTGCCTGG AACTCCACTC CAGGAGCTTA AAGAGAGCCA

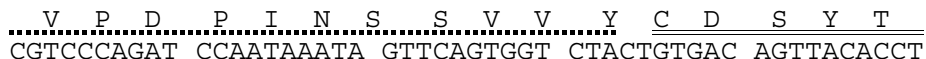
\begin{tabular}{lllllllllllllllll}
$\mathrm{Y}$ & $\mathrm{C}$ & $\mathrm{P}$ & $\mathrm{D}$ & $\mathrm{G}$ & $\mathrm{T}$ & $\mathrm{T}$ & $\mathrm{C}$ & $\mathrm{C}$ & $\mathrm{R}$ & $\mathrm{H}$ & $\mathrm{P}$ & $\mathrm{Q}$ & $\mathrm{G}$ & $\mathrm{G}$ & $\mathrm{W}$ & $\mathrm{T}$ \\
\hline
\end{tabular} ACTGTCCTGA TGgCACtACT TGCTgCAgAC ACCCACAAgG AggCtgGACC

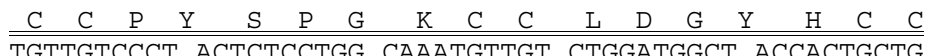
$\begin{array}{llllllllllllllll}P & I & G & F & D & C & D & R & T & Y & Q & H & C & V & R & E\end{array}$ TCCAATTGGA TTTGACTGTG ACCGCACCTA CCAGCACTGT GTGAGGGAAA

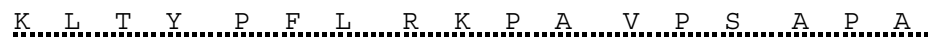
AАСTCACATA TCCTTTCCTC CGCAAGCCAG CAGTGCCTTC AGCACCTGCC

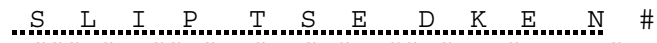

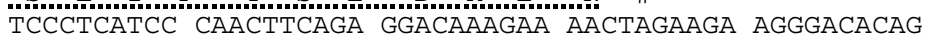

Fig. 1. (A) Schematic presentation of sequencing strategy used to obtain the tilapia pgrn sequence. Thick closed boxes represent the grn repeats; thin closed boxes represent the intervening spacer regions (GAP); Thin line represent the 5'UTR and $3^{\prime} \mathrm{UTR}$; and the arrow box represents the signal sequence. $3^{\prime}$ RACE primer site (P1) and the PCR primers (P2F and P2R) are shown below.(B) Nucleotide sequence and the deduced amino acid sequence of the tilapia pgrn. The nucleotides and amino acids are numbered from the GAA and methionine (M), respectively. The stop codon is shown by a number sign. Double underlined sequences correspond to the grn repeats. Underlined sequences correspond to the signal peptide. Dash line sequences correspond to the GAP. Amino acid sequence is presented above and the nucleotide sequence is presented below.

\subsection{Western blot analysis of liver pgrn protein}

One hundred to $400 \mathrm{mg}$ of liver samples were collected from 3-4 GHtreated or control fish at various time intervals $(0,1,3,6,12,24 \mathrm{~h}, 3$ day and 5 day). The liver samples were washed twice in an ice-cold phosphate-buffered saline (PBS) containing phenyl-methylsulfonyluoride (PMSF; $200 \mu \mathrm{M}$ ), weighed and then homogenized in a imidazole- $\mathrm{HCl}$ buffer $(100 \mathrm{mM}, \mathrm{pH} 7.0$, 5) containing $5 \mathrm{mM} \mathrm{Na}_{2}$ EDTA, $200 \mathrm{mM}$ sucrose, $0.1 \%$ sodium deoxycholate and 1 CØmplete ${ }^{\mathrm{TM}}$ (EDTA-free, a protease inhibitor cocktail tablet) with a motorized Teflon pestle at $1000 \mathrm{rpm}$ for $2 \mathrm{~min}$. The lysate was incubated at $4{ }^{\circ} \mathrm{C}$ for $15 \mathrm{~min}$ with rocking and insoluble material was pelleted by microcentrifugation for $20 \mathrm{~min}$ at $16,000 \mathrm{~g}$. After centrifugation, the supernatant was kept at $-70^{\circ} \mathrm{C}$ until used for immunoblotting. The total protein was determined with a Bio-Rad protein assay kit (Bio-Rad, Hercules, CA) and bovine serum albumin (Fraction V., Sigma, St. Louis, MO) was used as a standard. The protein samples were denatured in a sample buffer $(50$ Tris- $\mathrm{Cl}, \mathrm{pH} 7.5)$ containing $5 \% 2$-mercaptoethanol and $0.1 \%$ SDS by boiling for $10 \mathrm{~min}$ and resolved by electrophoresis in a $4-12 \%$ gradient polyacrylamide precast gel containing $0.1 \%$ SDS (NuPage, Invitrogen) at a constant $200 \mathrm{~V}$. The proteins were visualized with staining by the Simply Blue SafeStain (Invitrogen Life Technologies, La Jolla, CA, USA). The proteins were transferred onto nitrocellulose $(0.2 \mu \mathrm{m}$ pore size, Amersham) using an XCELL SureLock Minicell and Blot Module according to the manufacturer's instructions. The resulting blots were blocked for $1 \mathrm{~h}$ with a gelatin blocking buffer $(0.25 \%$ gelatin,
$50 \mathrm{mM} \mathrm{NaCl}, 0.05 \%$ Tween $^{\circledR}$ 20, $50 \mathrm{mM}$ Tris-HCl, pH 7.5, 5 mM EDTA) and probed with a 1:300 dilution of anti-human acrogranin (pgrn) goat polyclonal $\mathrm{Ab}$ (1 h room temp with shaking; $0.2 \mathrm{mg} / \mathrm{mL}$, acrogranin S-15, Santa Cruz Biotechnology, Santa Cruz, CA) or probed with a 1:3750 dilution of anti-chicken actin mouse monoclonal $\mathrm{Ab}$ ( $1 \mathrm{~h}$ room temp with shaking; Chemicon Biotechnology) in PBST (PBS plus $0.1 \%$ Tween 20)/gelatin. After washing in PBST $\left(3 \times, 5-10^{\prime}\right.$ each wash), the blots were probed with 1:20,000 HRP-conjugated Anti-goat IgG (Pierce Chemical Company, Rockford, IL) or anti-mouse IgG (Pierce Chemical Company, Rockford, IL) in PBST/gelatin ( $1 \mathrm{~h}$ room temp with shaking), washed in PBST $\left(3 \times, 5-10^{\prime}\right.$ each wash) again. The SuperSignal ${ }^{\circledR}$ West Femto (Pierce) were prepared by mixing one part of the Luminol/Enhancer Solution and one part of the Stable Peroxide Solution. The membranes were incubated with the substrates for various periods of time and placed in plastic sheet protectors prior to exposure to the ChemiGenius ${ }^{2}$ Low Light Imaging System using a F1.2 zoom lens with GeneTools Software (Syngene, Cambridge, UK).

\section{Results and discussion}

\subsection{Isolation of progranulin cDNA}

A 701 bp cDNA was cloned from tilapia liver RNA by $3^{\prime}$ RACE. Nucleotide sequence determination of the cloned 
Table 1

Sequence homology among grn peptides of different animal species

\begin{tabular}{|c|c|c|c|c|c|c|c|c|c|c|c|c|}
\hline \multirow[t]{2}{*}{ Species } & \multicolumn{12}{|c|}{ Top/similarity, bottom/divergence ( $\%)$} \\
\hline & Om1 & Om2 & $\mathrm{Cc1}$ & $\mathrm{Cc} 2$ & $\mathrm{Cc} 3$ & Hs1 & Hs2 & Hs3 & Hs4 & Hs5 & Hs6 & Hs 7 \\
\hline Om1 & & 43 & 38 & 38 & 40 & 36 & 48 & 50 & 43 & 46 & 45 & 40 \\
\hline $\mathrm{Om} 2$ & 12 & & 57 & 50 & 52 & 36 & 43 & 43 & 50 & 45 & 45 & 46 \\
\hline $\mathrm{Cc} 1$ & 12 & 7 & & 78 & 81 & 34 & 41 & 45 & 46 & 38 & 45 & 40 \\
\hline $\mathrm{Cc} 2$ & 12 & 9 & 7 & & 90 & 31 & 38 & 41 & 43 & 40 & 40 & 45 \\
\hline $\mathrm{Cc} 3$ & 9 & 7 & 3 & 3 & & 34 & 40 & 43 & 46 & 41 & 41 & 45 \\
\hline Hs1 & 12 & 10 & 9 & 10 & 10 & & 33 & 34 & 41 & 43 & 40 & 36 \\
\hline Hs2 & 7 & 5 & 12 & 12 & 9 & 7 & & 52 & 48 & 41 & 45 & 40 \\
\hline Hs3 & 12 & 9 & 10 & 12 & 9 & 9 & 21 & & 50 & 50 & 40 & 36 \\
\hline Hs4 & 16 & 3 & 9 & 10 & 9 & 12 & 7 & 12 & & 55 & 53 & 50 \\
\hline Hs5 & 10 & 9 & 9 & 12 & 10 & 17 & 7 & 10 & 9 & & 52 & 41 \\
\hline Hs6 & 14 & 9 & 5 & 12 & 10 & 14 & 9 & 16 & 12 & 12 & & 41 \\
\hline Hs7 & 10 & 3 & 9 & 7 & 7 & 9 & 5 & 9 & 5 & 12 & 10 & \\
\hline
\end{tabular}

Comparison of tilapia grn repeats, carp grn repeats and human grn repeats. Numbers indicate percentage of amino acid similarity (top) and divergence (bottom) among these grn repeats. The abbreviation of species represent by species name. Om (Oreochromis mossambicus), Cc (Cyprinus carpio), Hs (Homo sapiens).

cDNA revealed that the clone contained an open reading frame of $621 \mathrm{bp}$ preceded by $65 \mathrm{bp}$ and followed by $15 \mathrm{bp}$ of $5^{\prime}$ - and $3^{\prime}$-untranslated regions, respectively. The open reading frame of the cDNA encodes a peptide of 206 aa with a estimated molecular weight of 22,600 (Fig. 1). Tilapia pgrn contains two fewer granulin (grn) repeats when compared with human pgrn, which contains seven and onehalf grn repeats (Bhandari and Bateman, 1992; Bhandari et al., 1992). Table 1 summarizes the sequence homology of grns from human, carp and tilapia. As shown in Table 1, grn1 and grn2 repeats in carp and human share similarities ranged from $31 \%$ to $57 \%$ with that of tilapia. The positions of the cysteine residues are highly conserved among grn1 and grn 2 of tilapia, carp and human (Fig. 2A). Furthermore, phylogenetic analysis of grn1 and grn2 from tilapia, carp and human revealed that while tilapia grn 2 is closer to carp grns, tilapia grn1 is the closest to human grn2 and grn3 (Fig. 2B).

\subsection{Tissue distribution tilapia pgrn $m R N A$}

Total RNA extracted from eye, brain, skin, muscle, heart, gill, kidney, spleen, fat, liver, stomach, intestine, cecum, and pancreas of tilapia at 1.5-month of age was subjected to RT-PCR analysis using pgrn specific oligonucleotides as amplification primers. The resulting PCR products
A

Omgranulinl Hsgranulin3 Hsgranulin2 Ccgranulinl Ccgranulin2 Ccgranulin 3 Omgranulin2 Hsgranulin7 Hsgranulin 1 Lmgranulin Hsgranulin4 Hsgranulin 5 Hsgranulin6 Consensus
- - CPD-GSTCSDTATCCKAKIG-FGCCPFPHAMCCADLLHCCPSGYRCNLVTMNC- - VMCPDARSRCPDGSTCCELPSGKYGCCPMPNATCCSDHLHCCPQDTVCDLIQSKCLAIQCPDSQFECPDFSTCCVMVDGSWGCCPMPQASCCEDRVHCCPHGAFCDLVHTRCI-VIHCDAATICPDGTTCCLSPYGVWYCCPFSMGQCCRDGI HCCRHGYHCDSTSTHCLR - VVYCNARTTCPSRTTCCRSPFGVWYCCPFLMGQCCRDGRHCCRHGYRCDSTSTLCLR - VVFCDAGITCPSGTTCCRSPFGVWYCCPFLMGQCCRDGR FCCRHGYHCDSTSTLCLR - - - CDSYTYCPDGTTCCRHPQGGWTCCPYSPGKCCLDGY HCCPI GFDCDRTYQHC - -DVECGEGHFCHDNQTCCRDNRQGWACCPYRQGVCCADRRHCCPAGFRCAARGTKCL- GGPCQVDAHCSAGHSCIFTVSGTS SCCPFPEAVACGDGHHCCPRGFHCSADGRSCF - - - SCTEKTCPGTETCCTTPQGEEGCCPYKEGVCCLDGIHCCPSGTVCDEDHRRCIQ -DVKCDMEVSCPDGYTCCRLQSGAWGCCPFTQAVCCEDHI HCCPAGFTCDTQKGTCE -

- - VPCDNVSSCPSSDTCCQLTSGEWGCCPIPEAVCCSDHQHCCPQGYTCVAEGQCQ - -

- - IGCDQHTSCPVGGTCCPSLGGSWACCQLPHAVCCEDRQHCCPAGYTCNVKARSCE$\begin{array}{lllllll}V & C D \\ T\end{array}$

B

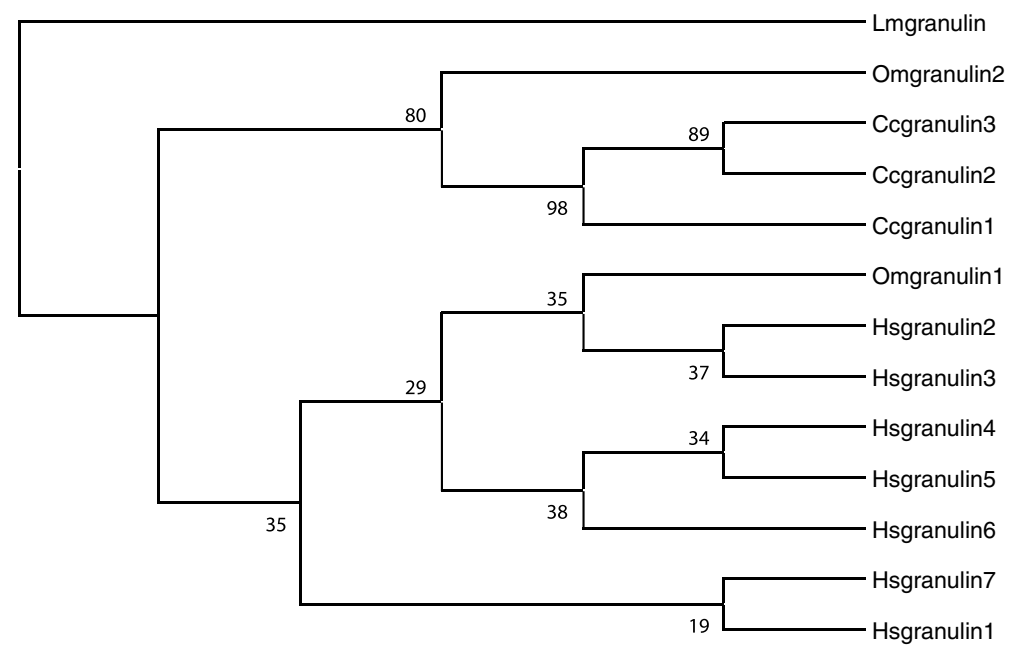

Fig. 2. Alignment of the deduced amino acid sequence and the dendrogram of granulin family members.(A) Alignment of the deduced amino acid sequences of grn domains in vertebrates and arthropods. Amino acid residues that are identical in all proteins are showed in light gray box, while residues conserved in proteins are presented other color. The amino acid of functional domains from various GRN proteins were compared by the Vector NTI 7 program.(B) Phylogenetic tree of GRN proteins was constructed by the UPGMA method using Molecular Evolutionary Genetics Analysis (MEGA 3) software. Locust GRN served as an out-group to root the tree. Bootstrap values from 1000 replicates were listed above branches. The abbreviation of species represent by species name. Om (Oreochromis mossambicus), Cc (Cyprinus carpio), Hs (Homo sapiens), Lm (Locusta migratoria). 
were resolved by agarose gel electrophoresis and quantified by densitometric analysis using Quantity One ${ }^{\circledR}$ software. The data was normalized over $18 \mathrm{~S}$ rRNA. As shown in Fig. 3, although pgrn mRNA was detected in all tissues analyzed, high levels of the pgrn mRNA were detected in spleen, intestine and pyloric cecum. Recently $\mathrm{He}$ et al. (2003) showed that pgrn may mediate wound healing response by accumulating neutrophils, marcrophages, blood vessels, and fibroblasts in the wound. It could also promote cell division, migration and the formation of capillary-like tubule structures in wound healing (Thornton et al., 1999). Our findings of high levels of pgrn mRNA in spleen and pyloric cecum agree with the results presented in the literature (Ashcroft et al., 2000; He et al., 2003).

The processed products of the pgrn have been identified in a variety of cells and tissues, including rat spleen (Bhandari et al., 1993), rat kidney cell (Plowman et al., 1992), horse neutrophil (Couto et al., 1992), haematopoietic organs of teleost fish (Belcourt et al., 1993), and rat hypothalamus (Suzuki and Nishiahara, 2002). Therefore, having the highest levels of pgrn mRNA in tilapia spleen observed in our studies may imply that grn protein plays a role in haematopoiesis. Grn proteins also have been detected in the immune cells (Barreda et al., 2004; Zhu et al., 2002), and grn A and B peptides have been purified from human leukocytes (Bhandari et al., 1992), demonstrating that the grn is translated and some of the precursor is cleaved into mature peptides. In mice, it has been demonstrated that the secretory leukocyte protease inhibitor (SLPI) can bind to the pgrn and inhibit the conversion of pgrn to grn by elastase (Zhu et al., 2002). However, it is unclear whether pgrn can be converted to grn in tilapia by the modulation of elastase, a molecule similar to SLPI.

\subsection{Dose-dependent and time course induction of pgrn $m R N A$ and pgrn peptide induced by GH in tilapia liver}

Dose dependency is a fundamental basis of a hormonal response. To confirm if the levels of pgrn and IGF-I mRNA are responsive to induction by exogenous recombinant seabream (rs) GH, tilapia of 1.5 months of age were fasted for 2 days prior to injection with various doses of rsGH and the levels of pgrn and IGF-I mRNA were determined by RNA Northern blotting. As shown in Fig. 4, while the pgrn and IGF-I mRNA levels exhibited a dosedependent increase with increasing levels of rbGH treatment, the magnitude of IGF-I mRNA response to GH is higher than that of pgrn mRNA.

Fig. 5 presents the results of the time course induction of IGF-I and pgrn mRNA. The level of IGF-I mRNA reached a plateau at $3 \mathrm{~h}$ after $\mathrm{GH}$ treatment and maintained at a slightly lower level until $6 \mathrm{~h}$, whereas pgrn mRNA reached its maximum level of induction at $3 \mathrm{~h}$ after hormone treatment and diminished thereafter (Fig. 5A). At the peak of induction, IGF-I and pgrn mRNA levels are at 2.7- and 2.5fold increase over mock injected controls. As shown in Fig. 2A, tilapia and human pgrns are highly conserved in the cysteine residues (Baba et al., 1993), and the protein
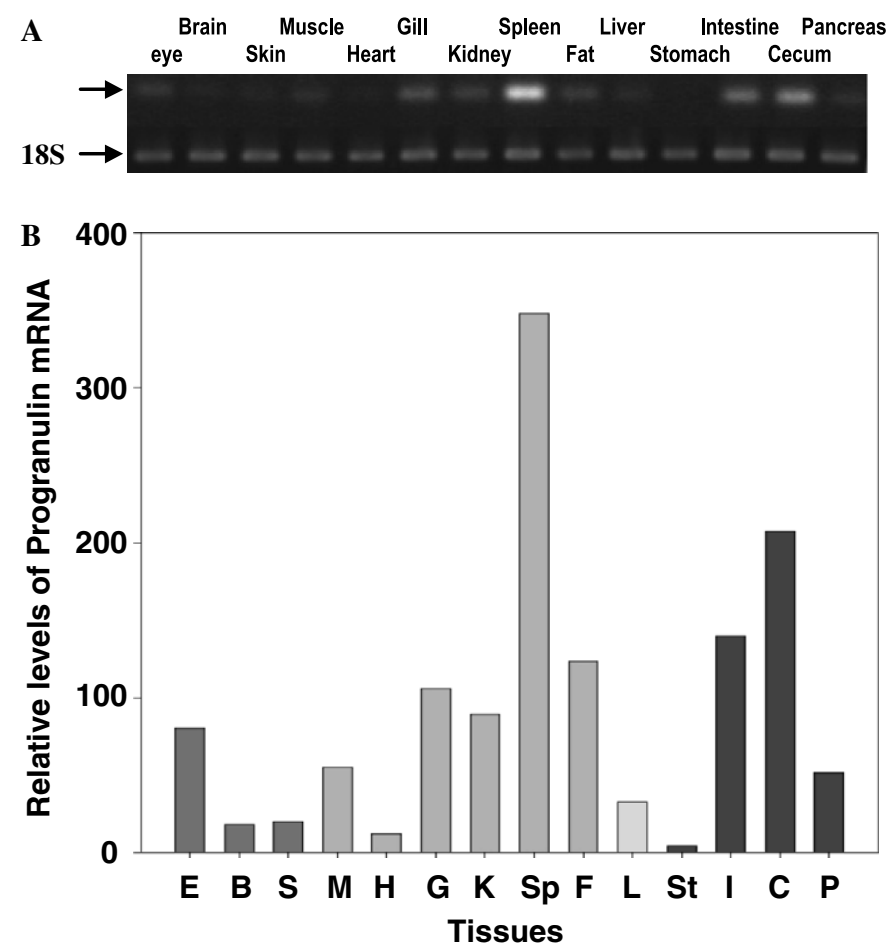

Fig. 3. Semi-quantitative RT-PCR analysis of pgrn mRNA in tilapia tissues. One microgram of total RNA from each tissue was used as the template for reverse transcription reaction and the resulting cDNA was PCR amplified for pgrn cDNA, using pgrn specific oligonucleotide as amplification primer. The resulting PCR product was analyzed on $1.2 \%$ agarose gels and the signals were corrected by using $18 \mathrm{~S}$ rRNA.(A) Electrophoresis patterns of the PCR products.(B) Relative levels of pgrn mRNA in tilapia tissues.

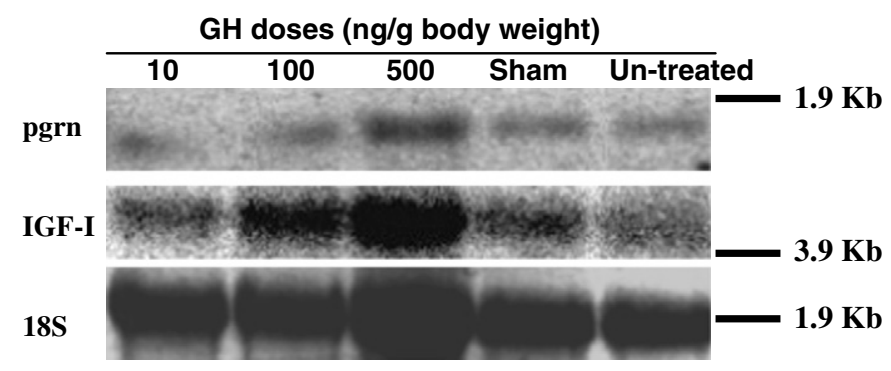

Fig. 4. Dose-dependent response of pgrn and IGF-I mRNA in livers after rbGH administration. The levels of pgrn and IGF-I mRNA were determined by Northern RNA blotting and each band was normalized with 18S rRNA. About 1.5-month old tilapia were administrated with different doses of GH (10, 100, $500 \mathrm{ng} / \mathrm{g}$ body weight) by i.p. injection. Conditions of transfer, blotting and hybridization were as described in Section 2.

modules are characterized by a motif of $\mathrm{X}_{2-3} \mathrm{CX}_{4-5}$ $\mathrm{CX}_{5} \mathrm{CCX}_{7-8} \mathrm{CCX}_{6} \mathrm{CCX}_{5} \mathrm{CCX}_{5} \mathrm{CX}_{6} \mathrm{CX}_{1-2}$ linked by six disulfide bridges. Due to this motif conservation (about $50 \%$ similarity), the anti-human pgrn antibody may be used to detect pgrn protein in the tilapia liver induced by GH. As shown in Fig. 5B, the results of immunoblot analysis showed that pgrn peptide was detected in the tilapia liver $12 \mathrm{~h}$ after $\mathrm{GH}$ treatment.

To our knowledge, this paper represents the first detailed analysis of the expression of pgrn gene in a teleost fish in 
A

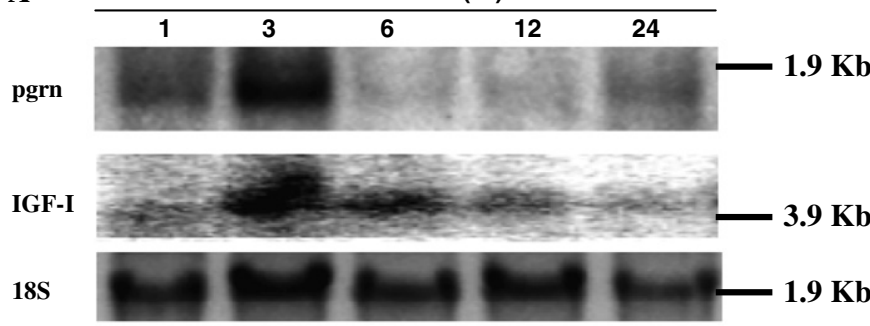

B

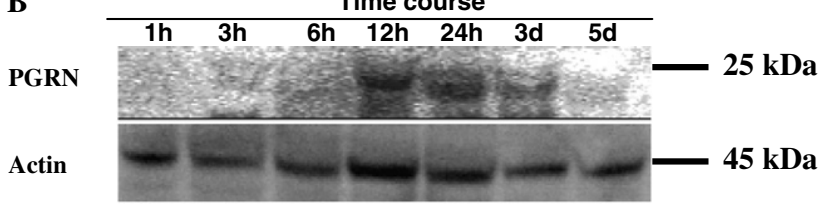

Fig. 5. Time course of appearance of pgrn and IGF-I mRNA and PGRN peptide in tilapia livers after intraperitoneal (i.p.) injection with $500 \mathrm{ng} / \mathrm{g}$ body weight of rbGH. Tilapia ( 1.5 months of age) received $500 \mathrm{ng} / \mathrm{g}$ body weight of rsGH by i.p. injection. The RNA samples were analyzed by RNA northern blot analysis and the signals were normalized with $18 \mathrm{~S}$ rRNA. Pgrm protein and actin were determined by immunoblotting as described in Section 2.(A) Pgrn and IGF-I mRNA at different time intervals after GH-treatment; (B) Pgrn protein in different time intervals after GH treatment.

response to exogenous rbGH treatment. Although the level of pgrn mRNA in the liver was low, a significant increase of pgrn mRNA is observed in the liver of 1.5 months old tilapia treated with $\mathrm{GH}$, suggesting that pgrn gene product may also be involved in the growth performance of the animal. This notion is further supported by the observation that high levels of pgrn mRNA are observed in the intestine and pyloric cecum. Recently, results of preliminary studies conducted in our laboratory with a transgenic zebrafish line (tglZf) expressing green fluorescent protein (GFP) in the liver (Her et al., 2003) showed that the knock down of pgrn gene with a morpholino antisense oligomer resulted in a significant inhibition of liver growth as compared to the controls (data unpublished). Although we do not have direct evidence to show the link of pgrn to fish growth, the co-induction of pgrn by GH in the liver with IGF-I and the reduction of liver growth in zebrafish treated with pgrn morpholino antisense may hint the importance of pgrn in growth regulation in this fish species.

\section{Acknowledgments}

This study was supported by grants from the Taiwan National Science Council [NSC 91-2317-B-001-010, NSC 92-2317-B-001-023-, and NSC93-2317-B-001-009-] to J.L.W. and from U.S. Department of Agriculture (CONS9803641) to T.T.C.

\section{References}

Ashcroft, G.S. et al., 2000. Secretory leukocyte protease inhibitor mediates non-redundant functions necessary for normal wound healing. Nat. Med. 6, 1147-1153.
Baba, T. et al., 1993. Acrogranin, an acrosomal cysteine-rich glycoprotein, is the precursor of the growth-modulating peptides, granulins, and epithelins, and is expressed in somatic as well as male germ cells. Mol. Reprod. Dev. 34, 233-243.

Baker, J. et al., 1993. Role of insulin-like growth factors in embryonic and postnatal growth. Cell 75, 73-82.

Barreda, D.R. et al., 2004. Differentially expressed genes that encode potential markers of goldfish macrophage development in vitro. Dev. Comp. Immunol. 28, 727-746.

Belcourt, D.R. et al., 1993. Isolation and primary structure of the three major forms of granulin-like peptides from hematopoietic tissues of a teleost fish (Cyprinus carpio). J. Biol. Chem. 268, 9230-9237.

Bhandari, V., Bateman, A., 1992. Structure and chromosomal location of the human granulin gene. Biochem. Biophys. Res. Commun. 188, 57-63.

Bhandari, V. et al., 1993. The complementary deoxyribonucleic acid sequence, tissue distribution, and cellular localization of the rat granulin precursor. Endocrinology 133, 2682-2689.

Bhandari, V. et al., 1992. Isolation and sequence of the granulin precursor cDNA from human bone marrow reveals tandem cysteine-rich granulin domains. Proc. Natl. Acad. Sci. USA 89, 1715-1719.

Butler, A.A., LeRoith, D., 2001. Minireview: tissue-specific versus generalized gene targeting of the igfl and igflr genes and their roles in insulinlike growth factor physiology. Endocrinology 142, 1685-1688.

Chen, M.H.-C. et al., 2001. The characterization of prepro-insulin-like growth factor-1 Ea-2 expression and insulin-like growth factor-1 genes (devoid $81 \mathrm{bp}$ ) in the zebrafish (Danio rerio). Gene 268, 67-75 (SCI).

Chen, M.H.-C. et al., 2004. Functional analysis of the insulin-like growth factor 1 receptor gene promoter in the zebrafish (Danio rerio). Mar. Biotechnol. (SCI) 6, S146-S152.

Couto, M.A. et al., 1992. Identification of eNAP-1, an antimicrobial peptide from equine neutrophils. Infect. Immun. 60, 3065-3071.

Hanington, P.C. et al., 2006. A novel hematopoietic granulin induces proliferation of goldfish (Carassius auratus L. macrophages). J. Biol. Chem. 281, 9963-9970.

He, Z., Bateman, A., 1999. Progranulin gene expression regulates epithelial cell growth and promotes tumor growth in vivo. Cancer Res. 59, 3222 3229 .

He, Z. et al., 2003. Progranulin is a mediator of the wound response. Nat. Med. 9, 225-229.

Her, G.M. et al., 2003. In vivo studies of liver-type fatty acid binding protein (L-FABP) gene expression in liver of transgenic zebrafish (Danio rerio). FEBS Lett. 538, 125-133.

Le Roith, D. et al., 2001. The somatomedin hypothesis: 2001. Endocr. Rev. $22,53-74$.

LeRoith, D. et al., 1995. Molecular and cellular aspects of the insulin-like growth factor I receptor. Endocr. Rev. 16, 143-163.

Liau, L.M. et al., 2000. Identification of a human glioma-associated growth factor gene, granulin, using differential immuno-absorption. Cancer Res. 60, 1353-1360.

Liu, J.P. et al., 1993. Mice carrying null mutations of the genes encoding insulin-like growth factor I (Igf-1) and type 1 IGF receptor (Igf1r). Cell $75,59-72$.

Lupu, F. et al., 2001. Roles of growth hormone and insulin-like growth factor 1 in mouse postnatal growth. Dev. Biol. 229, 141-162.

Miller, W.L., Eberhardt, N.L., 1983. Structure and evolution of the growth hormone gene family. Endocr. Rev. 4, 97-130.

Nijhout, H.F., 2003. The control of growth. Development 130, 5863-5867.

Plowman, G.D. et al., 1992. The epithelin precursor encodes two proteins with opposing activities on epithelial cell growth. J. Biol. Chem. 267, 13073-13078.

Rechler, M.M., 1997. Growth inhibition by insulin-like growth factor (IGF) binding protein-3-what's IGF got to do with it? Endocrinology $138,2645-2647$.

Romano, G., 2003. The complex biology of the receptor for the insulin-like growth factor-1. Drug News Perspect. 16, 525-531.

Shamblott, M.J. et al., 1995. Appearance of insulin-like growth factor mRNA in the liver and pyloric ceca of a teleost in response to 
exogenous growth hormone. Proc. Natl. Acad. Sci. USA 92, $6943-$ 6946.

Shoyab, M. et al., 1990. Epithelins 1 and 2: isolation and characterization of two cysteine-rich growth-modulating proteins. Proc. Natl. Acad. Sci. USA 87, 7912-7916.

Suzuki, M., Nishiahara, M., 2002. Granulin precursor gene: a sex steroidinducible gene involved in sexual differentiation of the rat brain. Mol. Genet. Metab. 75, 31-37.
Thornton, M.A. et al., 1999. The human platelet alphallb gene is not closely linked to its integrin partner beta3. Blood 94, 2039-2047.

$\mathrm{Xu}$, S.Q. et al., 1998. The granulin/epithelin precursor abrogates the requirement for the insulin-like growth factor 1 receptor for growth in vitro. J. Biol. Chem. 273, 20078-20083.

Zhu, J. et al., 2002. Conversion of proepithelin to epithelins: roles of SLPI and elastase in host defense and wound repair. Cell 111, 867-878. 